\title{
$\alpha$-Synuclein dimers as potent inhibitors of fibrillization
}

Yevhenii A. Kyriukha, Kseniia Afitska, Andrii S. Kurochka, Shubhra Sachan, Maksym Galkin

Dmytro A. Yushchenko, and Volodymyr V. Shvadchak

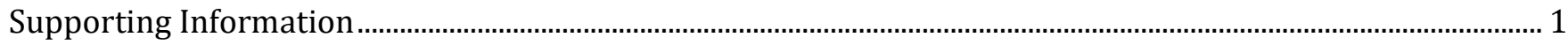

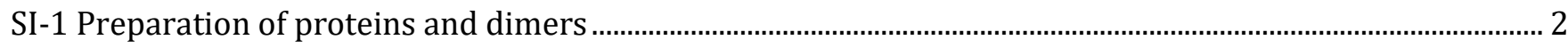

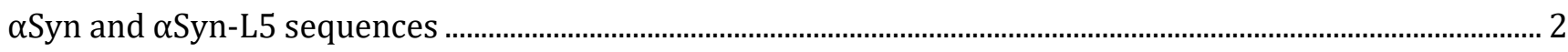

Table S1. Characterization of prepared dimers and proteins …........................................................................... 3

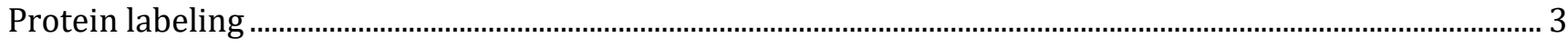

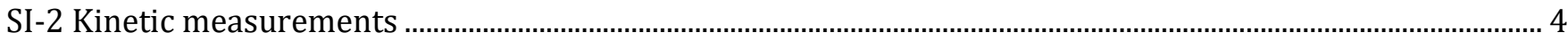

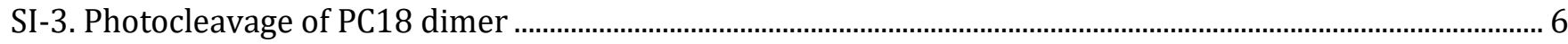

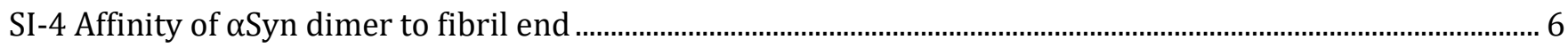

$\alpha$ Syn dimer binds to fibril ends and not to long sides of fibrils or to monomers. .............................................. 6

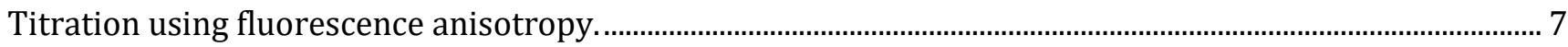

Relationship between $\mathrm{IC}_{50}$ and affinity of inhibitor to the fibril end.................................................................... 7

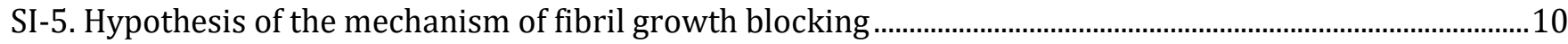

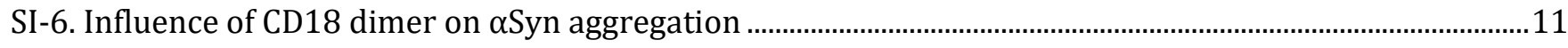

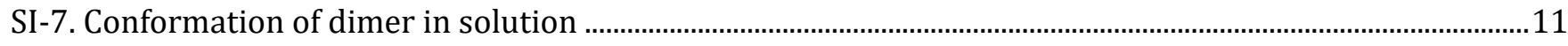

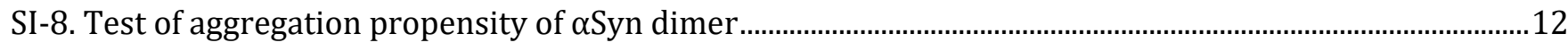




\section{SI-1 Preparation of proteins and dimers}

\section{$\alpha$ Syn and $\alpha$ Syn-L5 sequences}

In the $\alpha$ Syn sequence the positions used for introduction of Cys are in bold red.

In the $\alpha$ Syn-L5 sequence the L5 domain is in blue and the linker between two proteins in in grey. Position 18 used for Cys mutation and further dimerization is in red.

\begin{tabular}{|c|c|c|c|c|c|c|}
\hline \multirow[t]{3}{*}{$\alpha$ Syn : } & & MDVFMKGLSK & AKEGVVAAAE & KTKQGVAEAA & GKTKEGVLYV & GSKTKEGVVH \\
\hline & & GVATVAEKTK & EQVTNVGGAV & VTGVTAVAQK & TVEGAGSIAA & ATGFVKKDQI \\
\hline & & GKNEEGAPQE & GILEDMPVDP & DNEAYEMPSE & EGYQDYEPEA & \\
\hline \multirow[t]{6}{*}{$\alpha$ Syn-L5 } & $S$ & MDVFMKGLSK & AKEGVVAAAE & KTKQGVAEAA & GKTKEGVLYV & GSKTKEGVVH \\
\hline & & GVATVAEKTK & EQVTNVGGAV & VTGVTAVAQK & TVEGAGSIAA & ATGFVKKDQI \\
\hline & & GKNEEGAPQE & GILEDMPVDP & DNEAYEMPSE & EGYQDYEPEA & ARGGSGGGSG \\
\hline & & QAVVTQEPSV & TVSPGGTVIL & TCGSGTGAVT & SGHYANWFQQ & KPGQAPRALI \\
\hline & & FDTDKKYSWT & PGRFSGSLLG & AKAALTISDA & QPEDEAEYYC & SLSDVDGYLE \\
\hline & & GGGTQLTVLS & & & & \\
\hline
\end{tabular}

Structures of used dimerizers and label<smiles>O=C1C=CC(=O)N1CCOCCOCCN1C(=O)C=CC1=O</smiles><smiles>[2H]C(C)(C)c1ccc(-c2ccc3cc2-c2ccc(N(CC)CC)cc2Oc2cc(N(CC)CC)ccc2O3)c(S(=O)(=O)O)c1</smiles><smiles>COc1cc(COC(=O)CCCN2C(=O)C=CC2=O)c([N+](=O)[O-])cc1OCCCN(C)C(=O)CCCC1C(=O)C=CC1=O</smiles><smiles>CNC(=O)C(CCCCNC(=O)CCCN1C(=O)C=CC1=O)NC(=O)CCCN1C(=O)C=CC1=O</smiles><smiles></smiles>

Chart S1. Structures of used dimerizers and label. 
Table S1. Characterization of prepared dimers and proteins

\begin{tabular}{|c|c|c|c|c|c|c|}
\hline Name & $\begin{array}{l}\text { Position of } \\
\text { dimerization }\end{array}$ & Link & $\begin{array}{l}\text { Deletions in } \\
\alpha \text { Syn sequence }\end{array}$ & MW expected & MW found & $\varepsilon, \mathrm{mol} \times \mathrm{L}^{-1} \times \mathrm{cm}^{-1}$ \\
\hline$\alpha$ Syn-L5 & - & monomer & - & 26769 & 26765 & 23000 (at $280 \mathrm{~nm}$ ) \\
\hline$(\alpha$ Syn-L5) 2 & 18 & disulfide & - & 53597 & 53600 & 45800 (at $280 \mathrm{~nm}$ ) \\
\hline SS9 & 9 & disulfide & - & 28950 & 28956 & 12000 (at $275 \mathrm{~nm}$ ) \\
\hline SS18 & 18 & disulfide & - & 28982 & 28981 & 12000 (at $275 \mathrm{~nm}$ ) \\
\hline SS24 & 24 & disulfide & - & 28868 & 28872 & 12000 (at $275 \mathrm{~nm})$ \\
\hline SS41 & 41 & disulfide & - & 29010 & 29010 & 12000 (at $275 \mathrm{~nm}$ ) \\
\hline SS60 & 60 & disulfide & - & 28868 & 28874 & 12000 (at $275 \mathrm{~nm}$ ) \\
\hline SS72 & 72 & disulfide & - & 28922 & 28926 & 12000 (at $275 \mathrm{~nm}$ ) \\
\hline SS90 & 90 & disulfide & - & 28982 & 28982 & 12000 (at $275 \mathrm{~nm}$ ) \\
\hline SS103 & 103 & disulfide & - & 28896 & 28899 & 12000 (at $275 \mathrm{~nm}$ ) \\
\hline SS122 & 122 & disulfide & - & 28896 & 28899 & 12000 (at $275 \mathrm{~nm}$ ) \\
\hline SS140 & 140 & disulfide & - & 28982 & 28988 & 12000 (at $275 \mathrm{~nm}$ ) \\
\hline CD18 & 18 & BM(PEG)2 & - & 29292 & 29292 & 12000 (at $275 \mathrm{~nm}$ ) \\
\hline PC18 & 18 & ONB-dimerizer & - & 29584 & 29589 & $6000(\text { at } 350 \mathrm{~nm})^{1}$ \\
\hline$(\alpha \operatorname{Syn})_{2}-\mathrm{SR}$ & 18 & SR-dimerizer & - & 30043 & 30050 & 90000 (at $565 \mathrm{~nm}$ ) \\
\hline ss18-d108 & 18 & disulfide & $\Delta(109-140)$ & 21636 & 21637 & 2800 (at $275 \mathrm{~nm}$ ) \\
\hline ss18-d124 & 18 & disulfide & $\Delta(125-140)$ & 25144 & 25145 & 2800 (at $275 \mathrm{~nm}$ ) \\
\hline ss4-dN & 4 & disulfide & $\Delta(9-30)$ & 24668 & 24668 & 12000 (at $275 \mathrm{~nm}$ ) \\
\hline$\alpha$ Syn- $\alpha$ Syn & - & \multicolumn{2}{|c|}{ two copies of $\alpha$ Syn } & 29358 & 29357 & 12000 (at $275 \mathrm{~nm}$ ) \\
\hline$\alpha$ Syn-SR & 18 & monomer & - & 15173 & 15176 & 90000 (at $565 \mathrm{~nm}$ ) \\
\hline
\end{tabular}

\section{Protein labeling}

$\alpha$ Syn-SR was prepared by labeling $\alpha$ Syn-A18C mutant with SR-label (Chart S1). Before labeling, the protein was incubated overnight with a twofold molar excess of TCEP to reduce possible disulfide bonds. Then, a protein solution $(200 \mu \mathrm{L}$ of $185 \mu \mathrm{M}$ in $10 \mathrm{mM}$ Tris- $\mathrm{HCl}$, pH 7.4 buffer) was mixed with 2.5 equiv. of the SR-label (as a solution in DMSO). The homogeneous solution was further shaken for $4 \mathrm{~h}$ at $4{ }^{\circ} \mathrm{C}$ (low temperature was used to minimize $\alpha$ Syn aggregation). After that an additional 2.5 equiv. of the label were added, and the reaction mixture was then incubated overnight at $4{ }^{\circ} \mathrm{C}$ with gentle shaking. The excess of unreacted label was removed by filtration through a Zeba Spin desalting column, 7k MWCO (Thermo Fisher Scientific), and the solution was centrifuged at $14000 \mathrm{~g}$ for $1 \mathrm{~min}$. The supernatant was carefully collected and filtered again through a new desalting column. Lastly, the resulting solution of labelled protein was protected from light and stored at $-20^{\circ} \mathrm{C}$ until used in fluorescence measurements. The concentration of labeled protein was determined by absorbance of the SulfoRhodamine B using $\varepsilon=90000 \mathrm{M}^{-1} \mathrm{~cm}^{-1}$ at $565 \mathrm{~nm}$. Covalent conjugation of protein with a fluorescent label was confirmed by ESI mass-spectrometry. The degree of labeling (or labeling efficiency) of protein-dye conjugate was $>90 \%$ (measured by absorbance). 


\section{SI-2 Kinetic measurements}

Fibrillization in the absence of seeds. Concentrated $\alpha$ Syn solution $(\sim 200 \mu \mathrm{M})$ was centrifuged for 40 min at $14000 \mathrm{~g}$ in order to remove oligomers and aggregates formed during freezing/thawing, then its concentration was measured using absorption. Two solutions of $100 \mu \mathrm{M} \alpha$ Syn with 0 and $1 \mu \mathrm{M}$ inhibitor respectively (650 $\mu \mathrm{l}$ ) were prepared from the concentrated $\alpha$ Syn solution by mixing it with buffer containing ThT, and with dimer solution or the same amount of water. Then each solution was transferred to a plate providing 12 parallel samples (50 $\mu \mathrm{l}$ per well). All studied dimers were tested on the same plate. The resulted kinetic curves were analyzed to obtain lag time (Figure S1), which was calculated as the time from the beginning of experiment till the fluorescence intensity reaches the value that corresponds to $10 \%$ fibrillized protein.
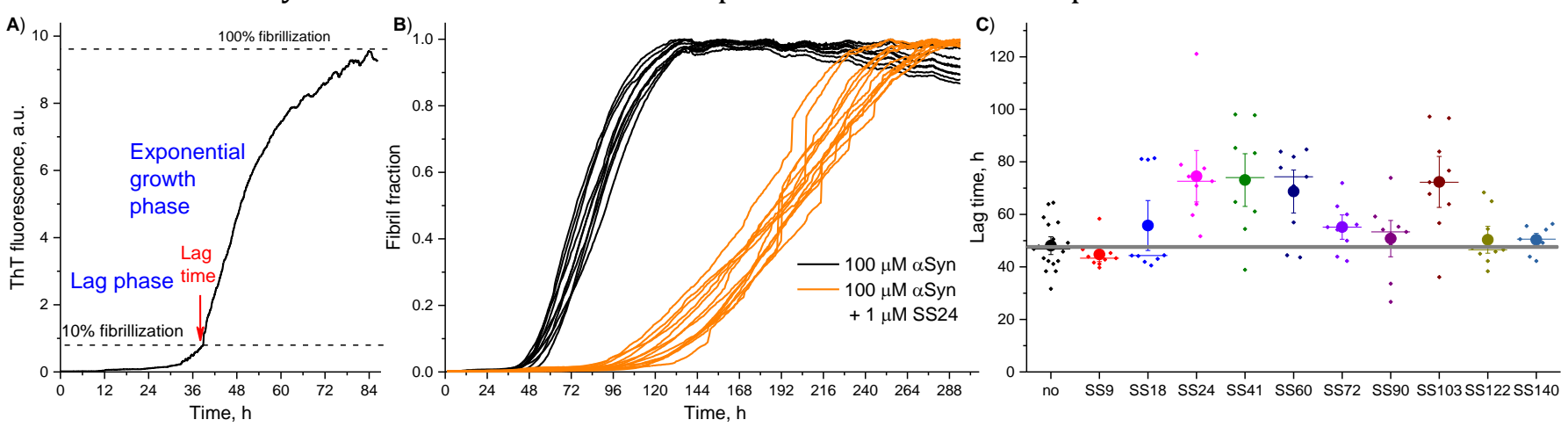

Figure S1. A) Determination of the fibrillization lag time from an experimental kinetic curve. B) Fibrillization of $100 \mu \mathrm{M} \alpha \mathrm{Syn}$ in the absence and in the presence of $1 \mu \mathrm{M}$ dimer SS24. 12 repeats. C) Lag times of unseeded fibrillization of $\alpha$ Syn $(100 \mu \mathrm{M})$ in the presence of different $\alpha$ Syn dimers $(1 \mu \mathrm{M})$. Values from 12 repeats for each dimer (small dots), average value with SD (bold dots and error bars), and median value (short horizontal lines). Thick grey line is the average for the lag time in the absence of dimers. 


\section{Fibrillization in the presence of seeds}
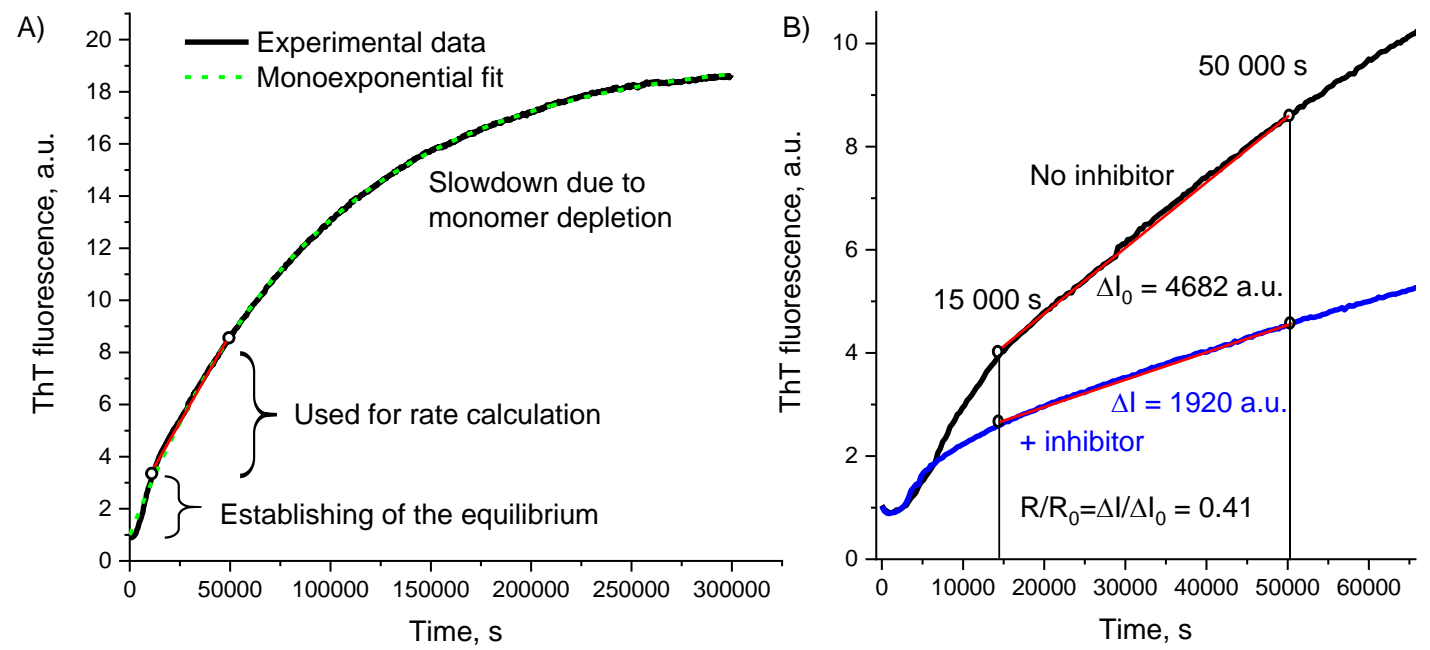

Figure S2. A) An example of the kinetic curve representing fibrillization of $\alpha$ Syn $(50 \mu \mathrm{M})$ in the presence of seeds (500 $\mathrm{nM}$ ). Experimental data (black) and fit to first order kinetic equation (green). The red line shows the region used for the rate calculation. B) Comparison of the kinetic curves in the absence of inhibitor (black, zoomed curve from panel A) and in the presence of inhibitor (blue). The ratio of reaction rates $\left(\mathrm{R} / \mathrm{R}_{0}\right)$ was calculated as the ratio of increases in ThT fluorescence intensity during the selected time frame (15 000-50 000 s).

A)

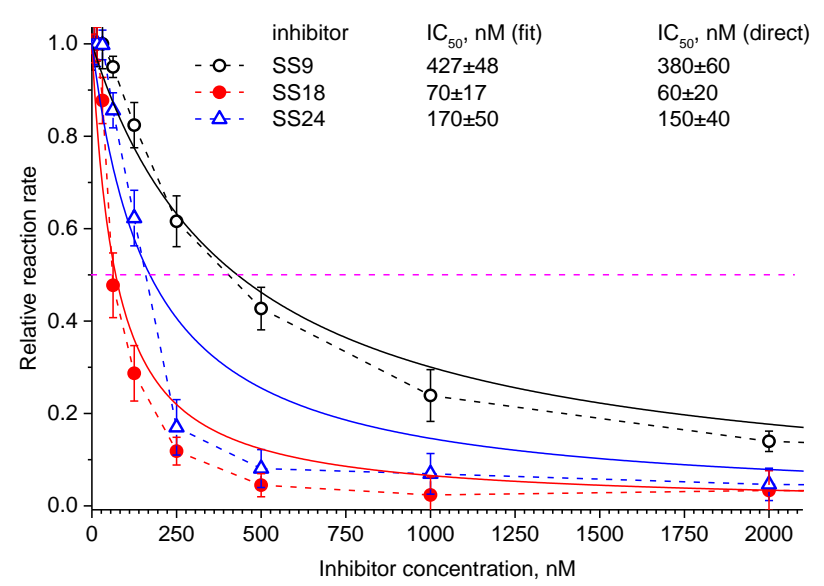

B)

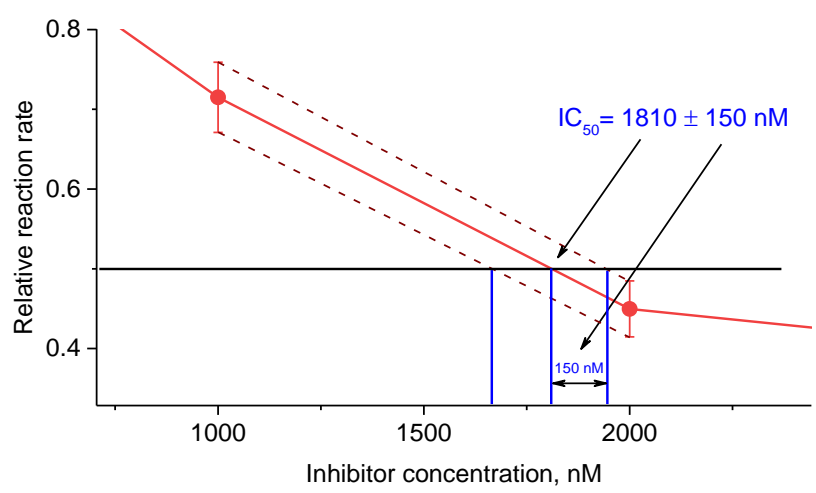

Figure S3. A) Determination of $\mathrm{IC}_{50}$ values for SS9, SS18, and SS24. IC 50 values were calculated by fitting the obtained experimental data by the equation $\mathrm{R} / \mathrm{R}_{0}=\mathrm{IC}_{50} /\left(\mathrm{IC}_{50}+\mathrm{C}_{\text {inhibitor}}\right.$ ) (see SI-5 for derivation). B) Calculation of $\mathrm{IC}_{50}$ values and confidence intervals by direct model-free analysis of the experimental points (used for inhibitors with $\mathrm{IC}_{50}>500 \mathrm{nM}$ ). 


\section{SI-3. Photocleavage of PC18 dimer}

We studied the kinetics of the photocleavage of PC18 dimer. $200 \mu \mathrm{l}$ of $40 \mu \mathrm{M}$ sample was irradiated with 365 nm UV light using the $350 \mathrm{~mW}$ Prizmatix MIC-LED-365B lamp. To follow the photocleavage progress, we took 15 $\mu \mathrm{l}$ aliquots after $1,2,4,8,16,32$, and 64 minutes and checked them by SDS-PAGE (Figure S4 A). Fractions of dimer were calculated based on integrated density of bands (determined by Integrated density function in Image software). $50 \%$ cleavage was reached after about 10 min of illumination (Figure S4 B).

A)

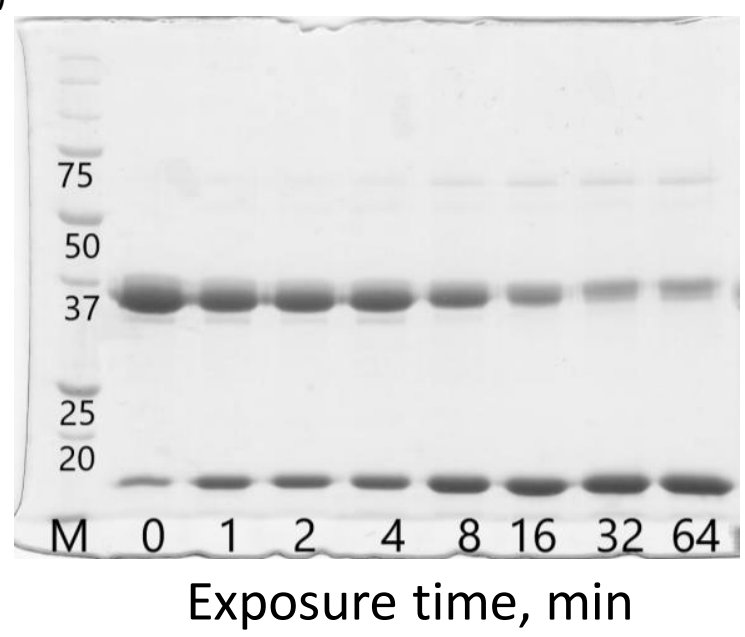

B)

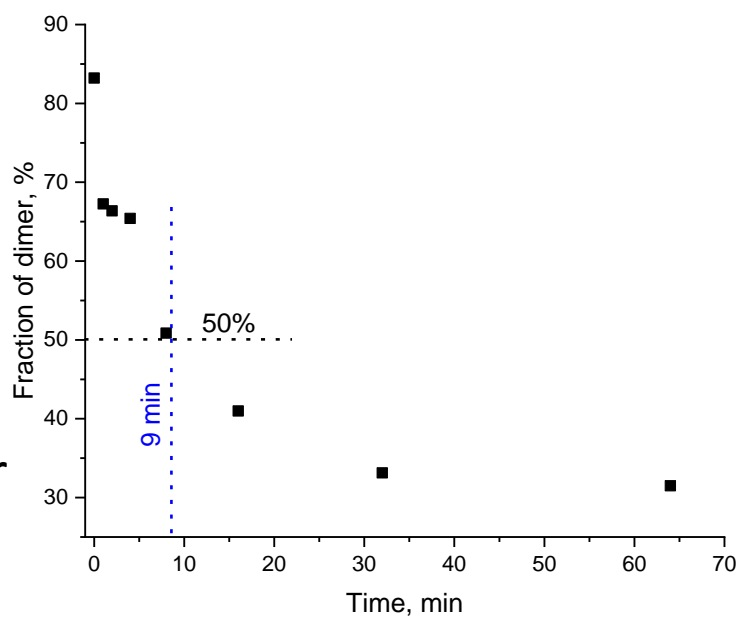

Figure S4. A) PC18 dimer photocleavage monitored by SDS PAGE and B) fraction of remaining dimer as a function of exposure time.

\section{SI-4 Affinity of $\alpha$ Syn dimer to fibril end}

\section{$\alpha$ Syn dimer binds to fibril ends and not to long sides of fibrils or to monomers.}

The addition of monomeric $\alpha$ Syn to the labeled dimer caused no changes in the fluorescence anisotropy. Incubation of the labeled dimer with short $\alpha$ Syn fibrils prepared by sonication led to a strong increase in anisotropy, indicating binding of the dimer to fibrils. Meanwhile, long fibrils resulted in much smaller increase of fluorescence anisotropy than short fibrils of the same protein concentration (Figure S5). The main difference between samples with short and long fibrils was the concentration of fibril ends, which was 20-fold higher in the case of short fibrils. ${ }^{2}$ Therefore, we conclude that the $\alpha$ Syn dimer efficiently interacts with $\alpha$ Syn fibril ends, but does not bind to monomeric $\alpha$ Syn or to long sides of fibrils (Figure S5).

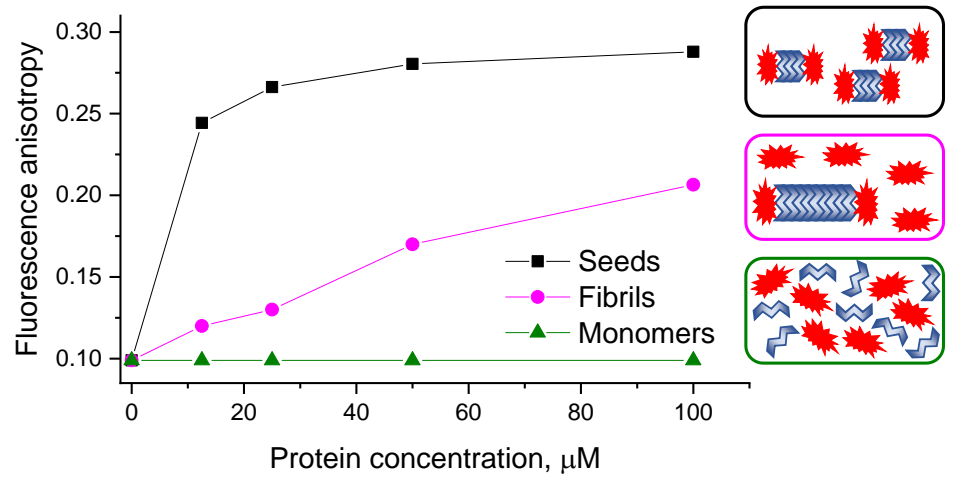

Figure S5. Interaction of labelled $\alpha$ Syn dimer ( $80 \mathrm{nM}$ ) with long $\alpha$ Syn fibrils, seeds and monomer, measured by fluorescence anisotropy. 


\section{Titration using fluorescence anisotropy.}

To determine affinity of $\alpha$ Syn dimer to fibril end, we titrated Rhodamine-labeled $\alpha$ Syn dimer ( $\alpha$ Syn) $)_{2}$-SR with short sonicated fibrils (seeds) and monitored the fraction of bound dimer using fluorescence anisotropy (Figure $2 \mathrm{~A}$ ). Fluorescence anisotropy depends on the mobility of the labeled molecule and increases from $\sim 0.1$ for free dimer in solution to $\sim 0.28$ for dimer bound to the fibril end.

We mixed $10 \mathrm{nM}$ labeled dimer $(\alpha \mathrm{Syn})_{2}$-SR) with different concentrations of seeds (0 to $100 \mu \mathrm{M}$ protein concentration) in separate eppendorf tubes. After $2 \mathrm{~h}$ of incubation, we measured the fluorescence anisotropy of each sample. The fraction of dimer bound to fibril end was calculated assuming that at the final titration point the binding was complete (Figure 2A). The same titration experiment was performed for labeled monomeric protein ( $\alpha$ Syn-SR) using the same batch of seeds. It shows that affinity of $\alpha$ Syn dimer to fibril ends is at least 5 -fold higher than affinity of monomeric $\alpha$ Syn.

Affinity of dimer to fibril end was calculated based on the fraction of free and bound dimers at given concentrations:

$$
\mathrm{K}_{\mathrm{d}}=\frac{[\mathrm{D}]_{\text {free }} \times[\mathrm{E}]}{[\mathrm{D}]_{\text {bound }}}=\frac{(1-\alpha) \times[\mathrm{E}]}{\alpha},
$$

where $K_{d}$ is the dissociation constant, $[D]_{\text {free }}$ and $[D]_{\text {bound }}$ are the concentration of free dimer in solution and dimer bound to fibril ends, $[E]$ is the concentration of free fibril ends and $\alpha$ is the fraction of bound dimer. The concentration of fibril ends was calculated based on the total concentration of fibrillized protein and the average length of fibrils $\left(50 \pm 20 \mathrm{~nm}\right.$, corresponding to $100 \pm 40$ monomers). ${ }^{3}$ We averaged the $K_{d}$ values obtained for different titration points, discarding ones with bound dimer fraction less than 0.2 or more than 0.8 because at those points the ratio of free and bound forms is too much affected by experimental errors.

The $K_{d}$ for dimer can be estimated as $30 \pm 20 \mathrm{nM}$ while affinity of monomer is much lower, $K_{d}=150 \pm 100 \mathrm{nM}$. High uncertainty of the values is caused mostly by the uncertainty in the concentration of free fibril ends.

\section{Relationship between $\mathrm{IC}_{50}$ and affinity of inhibitor to the fibril end}

$\mathrm{IC}_{50}$ of inhibitor is determined by the fraction of blocked fibrils at given inhibitor concentration. There are two processes that can induce reactivation of blocked fibril: 1) dissociation of inhibitor (that is determined by its affinity to fibril end) and 2) binding of monomer to inhibitor-blocked fibril that converts it to the fibril, which ends with amyloid-folded $\alpha$ Syn and therefore able to grow (Fig S6).

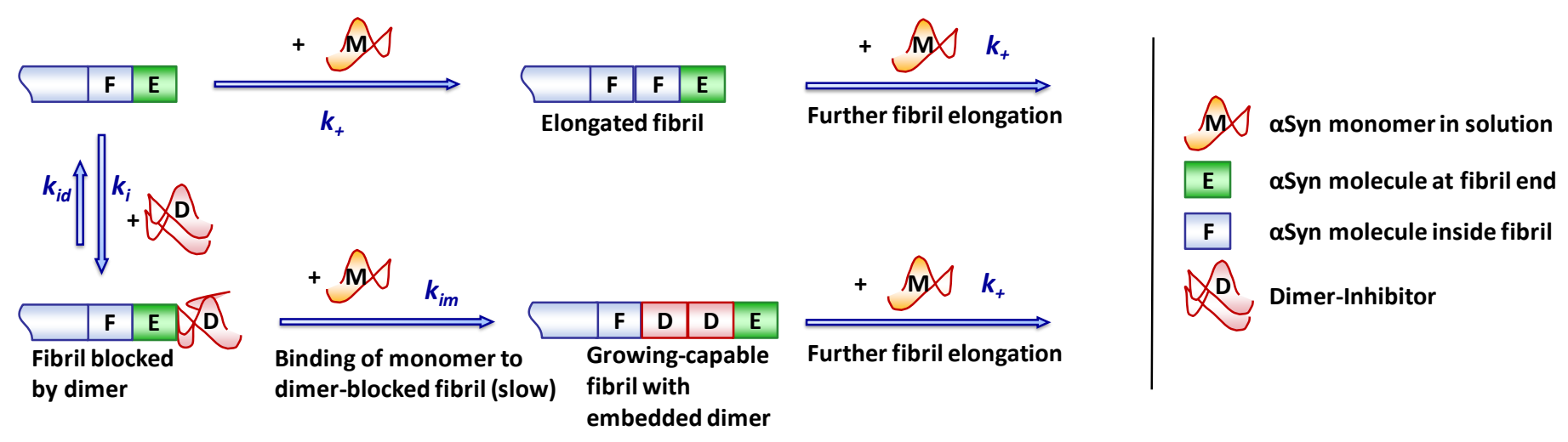

Figure S6. Kinetic scheme of $\alpha$ Syn fibrillization in the presence of dimer

The fibrillization reaction rate in the presence of dimer is proportional to the concentration of free (nonblocked) fibril ends.

$$
\frac{\mathrm{R}}{\mathrm{R}_{0}}=\frac{[\mathrm{E}]}{[\mathrm{E}]_{0}}
$$


where $R$ and $R_{0}$ are the rates in the presence and in the absence of inhibitor, and $[E]$ and $[E]_{0}$ are the concentration of active (non-blocked) fibril ends in the presence and in the absence of inhibitor.

The rate of blocking fibril ends is equal to:

$\mathrm{R}_{\mathrm{bl}}=\mathrm{k}_{\mathrm{i}}[\mathrm{D}][\mathrm{E}]$,

where [D] is the concentration of inhibitor (dimer) and $\mathrm{k}_{\mathrm{i}}$ is rate constant of inhibitor binding to the fibril end. The rate of fibril reactivation is the sum of inhibitor dissociation rate and rate of monomer binding to blocked fibril end (see Figure S5):

$$
\mathrm{R}_{\text {react }}=\mathrm{k}_{\mathrm{id}}[\mathrm{ED}]+\mathrm{k}_{\mathrm{im}}[\mathrm{ED}][\mathrm{M}]=[\mathrm{ED}]\left(\mathrm{k}_{\mathrm{id}}+\mathrm{k}_{\mathrm{im}}[\mathrm{M}]\right)
$$

where [ED] is the concentration of blocked fibril ends and [M] is the concentration of monomeric $\alpha$ Syn, $k_{i d}$ and $\mathrm{k}_{\mathrm{im}}$ are the rate constants of inhibitor dissociation from fibril end and monomer binding to inhibitor-blocked fibril end, respectively.

For time scales much longer than the time needed for inhibitor binding/dissociation, one can assume equilibrium between the binding/dissociation of inhibitor where $\mathrm{R}_{\mathrm{bl}}=\mathrm{R}_{\text {react }}$.

$$
\begin{aligned}
& \mathrm{k}_{\mathrm{i}}[\mathrm{D}][\mathrm{E}]=[\mathrm{ED}]\left(\mathrm{k}_{\mathrm{id}}+\mathrm{k}_{\mathrm{im}}[\mathrm{M}]\right) ; \\
& \frac{[\mathrm{E}]}{[\mathrm{ED}]}=\frac{\mathrm{k}_{\mathrm{id}}+\mathrm{k}_{\mathrm{im}}[\mathrm{M}]}{\mathrm{k}_{\mathrm{i}}[\mathrm{D}]}
\end{aligned}
$$

The total concentration of free and blocked fibril ends is equal to the concentration of fibril ends in the absence of inhibitor:

$$
\begin{aligned}
& {[\mathrm{E}]_{0}=[\mathrm{ED}]+[\mathrm{E}] ;} \\
& \frac{[\mathrm{E}]}{[\mathrm{E}]_{0}-[\mathrm{E}]}=\frac{\mathrm{k}_{\mathrm{id}}+\mathrm{k}_{\mathrm{im}}[\mathrm{M}]}{\mathrm{k}_{\mathrm{i}}[\mathrm{D}]} ; \\
& \frac{[\mathrm{E}]}{[\mathrm{E}]_{0}}=\frac{\mathrm{k}_{\mathrm{id}}+\mathrm{k}_{\mathrm{im}}[\mathrm{M}]}{\mathrm{k}_{\mathrm{i}}[\mathrm{D}]+\mathrm{k}_{\mathrm{id}}+\mathrm{k}_{\mathrm{im}}[\mathrm{M}]},
\end{aligned}
$$

where $[D]$ and $[M]$ are concentrations of dimer and monomer in solution, $[E]_{0}$ is total concentration of fibril ends (free and dimer-blocked), [E] is the concentration of free fibril ends.

Defining dissociation constant of dimer from fibril end as $K_{d}=\mathrm{k}_{\mathrm{id}} / \mathrm{k}_{\mathrm{i}}$,

$$
\frac{[\mathrm{E}]}{[\mathrm{E}]_{0}}=\frac{\frac{\mathrm{k}_{\mathrm{id}}}{\mathrm{k}_{\mathrm{i}}}+\frac{\mathrm{k}_{\mathrm{im}}}{\mathrm{k}_{\mathrm{i}}}[\mathrm{M}]}{[\mathrm{D}]+\frac{\mathrm{k}_{\mathrm{id}}}{\mathrm{k}_{\mathrm{i}}}+\frac{\mathrm{k}_{\mathrm{im}}}{\mathrm{k}_{\mathrm{i}}}[\mathrm{M}]}=\frac{\mathrm{K}_{\mathrm{d}}+\frac{\mathrm{k}_{\mathrm{im}}}{\mathrm{k}_{\mathrm{i}}}[\mathrm{M}]}{[\mathrm{D}]+\mathrm{K}_{\mathrm{d}}+\frac{\mathrm{k}_{\mathrm{im}}}{\mathrm{k}_{\mathrm{i}}}[\mathrm{M}]} .
$$

At the point that corresponds to $\mathrm{IC}_{50}$, the reaction rate is decreased twice, therefore

$$
\begin{aligned}
& \frac{[\mathrm{E}]}{[\mathrm{E}]_{0}}=0.5 \\
& {[\mathrm{D}]=\mathrm{IC}_{50}}
\end{aligned}
$$

So, the expression can be rewritten as

$$
0.5=\frac{\mathrm{K}_{\mathrm{d}}+\frac{\mathrm{k}_{\mathrm{im}}}{\mathrm{k}_{\mathrm{i}}}[\mathrm{M}]}{\mathrm{IC}_{50}+\mathrm{K}_{\mathrm{d}}+\frac{\mathrm{k}_{\mathrm{im}}}{\mathrm{k}_{\mathrm{i}}}[\mathrm{M}]},
$$

or, what is the same,

$$
\mathrm{IC}_{50}+\mathrm{K}_{\mathrm{d}}+\frac{\mathrm{k}_{\mathrm{im}}}{\mathrm{k}_{\mathrm{i}}}[\mathrm{M}]=2\left(\mathrm{~K}_{\mathrm{d}}+\frac{\mathrm{k}_{\mathrm{im}}}{\mathrm{k}_{\mathrm{i}}}[\mathrm{M}]\right) \text {, }
$$


$\mathrm{IC}_{50}=\mathrm{K}_{\mathrm{d}}+\frac{\mathrm{k}_{\mathrm{im}}}{\mathrm{k}_{\mathrm{i}}}[\mathrm{M}]$.

So, $\mathrm{IC}_{50} \geq \mathrm{K}_{\mathrm{d}}$.

For inhibitors active at low concentrations, $\mathrm{k}_{\mathrm{i}}>>\mathrm{k}_{\mathrm{im}}$.

Using this expression for $\mathrm{IC}_{50}$ we can provide a simple equation for fitting relationship between the relative fibril growth rate and inhibitor concentration:

$$
\frac{\mathrm{R}}{\mathrm{R}_{0}}=\frac{[\mathrm{E}]}{[\mathrm{E}]_{0}}=\frac{\mathrm{K}_{\mathrm{d}}+\frac{\mathrm{k}_{\mathrm{im}}}{\mathrm{k}_{\mathrm{i}}}[\mathrm{M}]}{[\mathrm{D}]+\mathrm{K}_{\mathrm{d}}+\frac{\mathrm{k}_{\mathrm{im}}}{\mathrm{k}_{\mathrm{i}}}[\mathrm{M}]}=\frac{\mathrm{IC}_{50}}{[\mathrm{D}]+\mathrm{IC}_{50}}
$$




\section{SI-5. Hypothesis of the mechanism of fibril growth blocking}

Affinity of a dimer to the $\alpha$ Syn fibril end is higher than affinity of the monomer. Therefore, we expect that it forms more intermolecular hydrogen bonds than monomer. This is possible only if both monomeric subunits of dimer are participating in the interaction. The N-termini of $\alpha$ Syn units in two filaments of unmodified $\alpha$ Syn fibril are on opposite sides of the fibril (distance $>4 \mathrm{~nm}$ ) while in the most active $\alpha$ Syn disulfide dimers $\mathrm{N}$-termini are linked together by a relatively short linker $(<1 \mathrm{~nm})$. Therefore, the dimer cannot bind to the fibril end repeating the conformation of two monomeric proteins in it.

There are two possibilities:

1) Both monomeric units of the dimer are bound in a conformation different from the conformation of monomers (Fig S7A). In this case each monomeric subunit of dimer will form less $\beta$-sheet structure than the molecule of WT $\alpha$ Syn in fibril. Therefore, the binding of monomer to the fibril end with a partially folded dimer will be much less energetically efficient.

2) One monomeric unit repeats the conformation of monomer at fibril end while other is bound only partially (Fig S7B). If this is the case, either blocking of one filament is sufficient for preventing elongation of the $\alpha$ Syn fibril, or the dimer binds to the fibril end in the way that weak-binding monomeric unit interact with both filaments (Fig 7B)

We do not have sufficient experimental data to distinguish these possibilities yet.

A

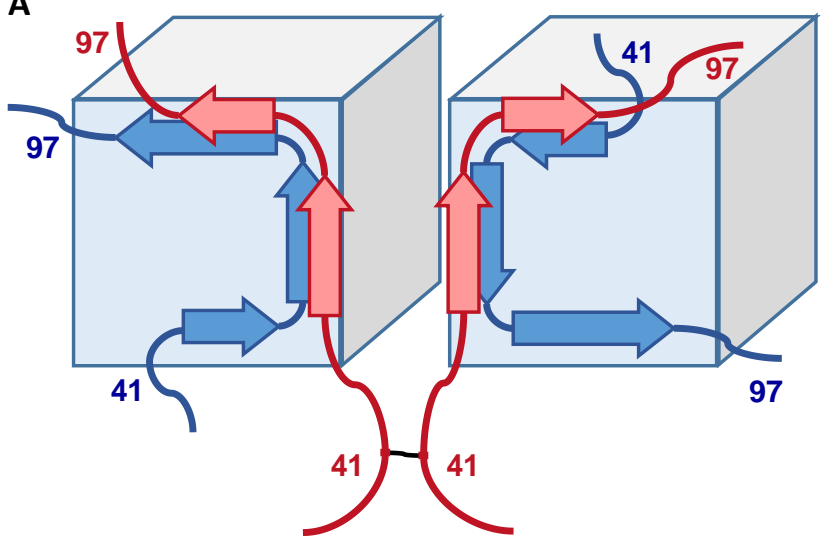

B

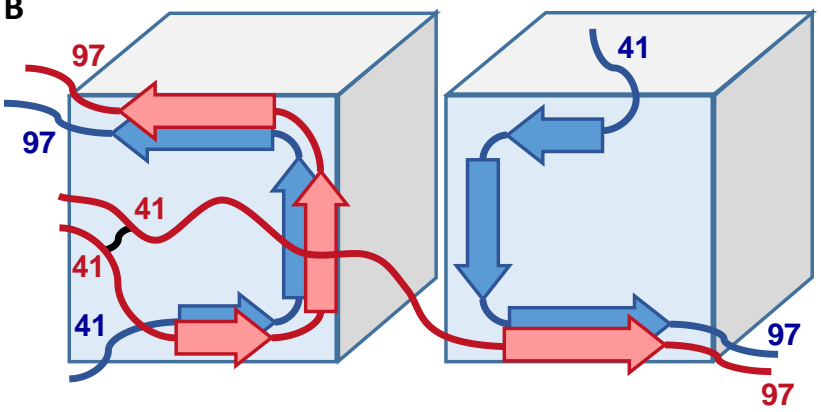

Figure S7. Schematic representations of two possible modes of $\alpha$ Syn dimer binding to the fibril end: A) both monomeric units bind in a conformation different from conformation of monomer, and B) one of monomeric unit repeats the conformation of monomer in fibril while other binds only partially and perturbs accessibility to the both filaments.

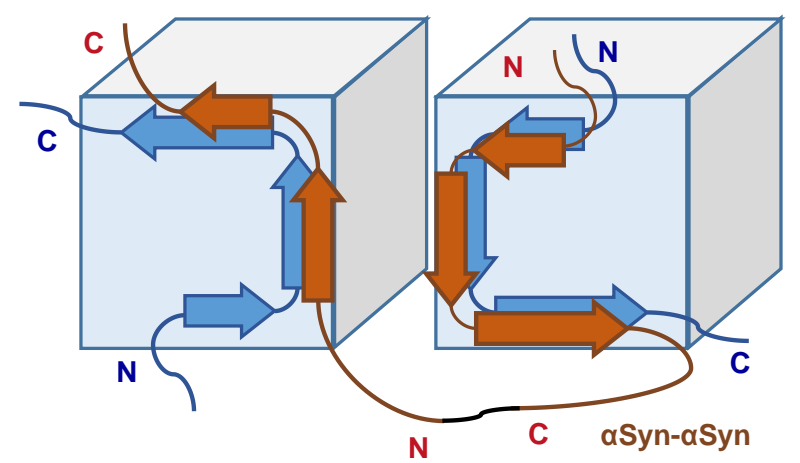

Figure S8. Schematic representations of binding of head-to-tail $\alpha$ Syn dimer to the end of $\alpha$ Syn fibril. 


\section{SI-6. Influence of CD18 dimer on $\alpha$ Syn aggregation}

We studied effect of the length of the linker between two monomeric units on the inhibition efficiency of dimers by comparing CD18 dimer with $\sim 1.5 \mathrm{~nm}$ long BM(PEG)2 bismaleimide linker to activity of dicysteine dimer SS18.
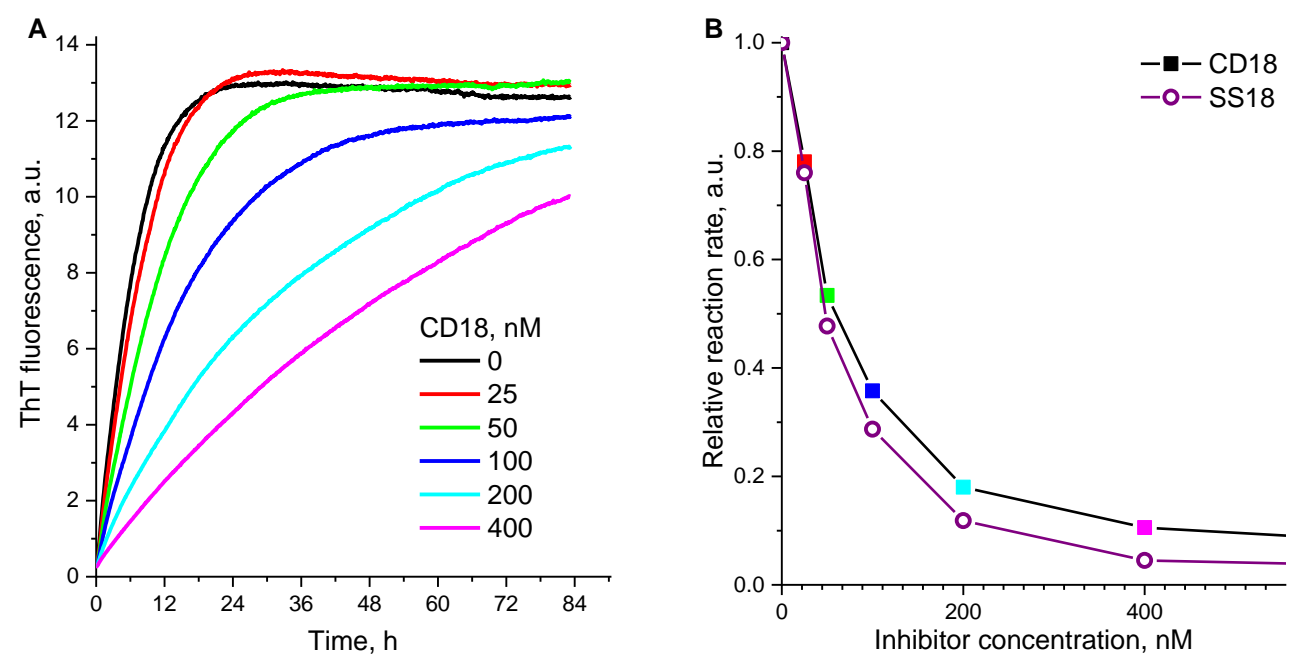

Figure S9. A) Influence of $\alpha$ Syn dimer CD18 on fibrillization of $\alpha$ Syn $(50 \mu \mathrm{M})$ in the presence of seeds $(0.5 \mu \mathrm{M})$. B) Relative initial fibrillization rate as a function of CD18 dimer concentration, calculated from data shown in the panel A compared with the data for SS18.

\section{SI-7. Conformation of dimer in solution}

To check if $\alpha$ Syn dimers in solution are in disordered conformation, similarly to monomeric $\alpha$ Syn, we compared CD spectra of $\alpha$ Syn monomer and SS9 dimer. Both of them show spectral shapes typical for unstructured proteins, namely, show no clear peaks at $217 \mathrm{~nm}$ (characteristic for $\beta$-sheet) or $222 \mathrm{~nm}$ (characteristic for $\alpha$-helix). Mean residue ellipticity of SS9 dimer at $217 \mathrm{~nm}$ is $3700 \mathrm{mdeg} \cdot \mathrm{cm}^{2} \cdot \mathrm{dmol}^{-1}$ that shows that total fraction of amino acids in $\beta$-sheet and $\alpha$-helix conformation is less than $15 \%$. So, we can conclude that $\alpha$ Syn dimer in buffer is unstructured, as well as monomeric $\alpha$ Syn.

$\alpha$ Syn monomer and dimer were prepared as described earlier and were stored at $-20{ }^{\circ} \mathrm{C}$ in the freezer. The proteins were unfreezed within $3 \mathrm{~h}$ before the CD measurements and centrifuged for $35 \mathrm{~min}$ at $13500 \mathrm{~g}$ to remove any possible aggregates formed during preparation steps.

To obtain spectra of $\alpha$ Syn in $\beta$-sheet form we used $\alpha$ Syn fibrils prepared upon seeded aggregation, controlled by ThT fluorescence. Fibrils were collected next day after the ThT fluorescence was reached the plateau level and were used within 1 week after preparation.

Membranes were in a form of SUVs (small unilamellar vesicles) composed of anionic lipid POPG (1-palmitoyl-2-oleoyl-sn-glycero-3-phospho-(1'-rac-glycerol)) that were shown to efficiently bind $\alpha$ Syn and induce its folding in a helical form. POPG was purchased in lyophilized form from Avanti Polar Lipids (Birmingham, USA). Stock solutions of $4 \mathrm{mM}$ were prepared in $\mathrm{CHCl}_{3}$ and stored in glass vials at $-20{ }^{\circ} \mathrm{C}$.. Aliquot of the stock solutions of POPG was added to clean glass flask and $\mathrm{CHCl}_{3}$ was removed under vacuum $(\sim 1 \mathrm{~h}, \sim 0.015$ bar). Then lipids were rehydrated in $10 \mathrm{mM} \mathrm{Na}^{-} \mathrm{PO}_{4}, \mathrm{pH} 7,150 \mathrm{mM} \mathrm{NaCl}$ buffer, to a final lipid concentration of 2 mM. Small unilamellar vesicles (SUVs) were prepared by sonication of the solution ("Ultrasonics" tip sonicator) for $50 \mathrm{~min}$. The resulting colloid solution was centrifuged $2 \mathrm{~min}$ at $1700 \mathrm{~g}$ to remove traces of metallic particles arising from the tip. The vesicles were used within 2 days after preparation.

CD spectra were recorded with a JASCO-J210 spectropolarimeter at room temperature using $2 \mathrm{~mm}$ path length cuvette, scanning from 250 to $200 \mathrm{~nm}$ with a scanning step of $0.2 \mathrm{~nm}$ and scanning speed of $100 \mathrm{~nm} / \mathrm{min}$, averages of 3 scans. Concentrations of samples were $2 \mu \mathrm{M}$. Data presented as mean residue ellipticities. 


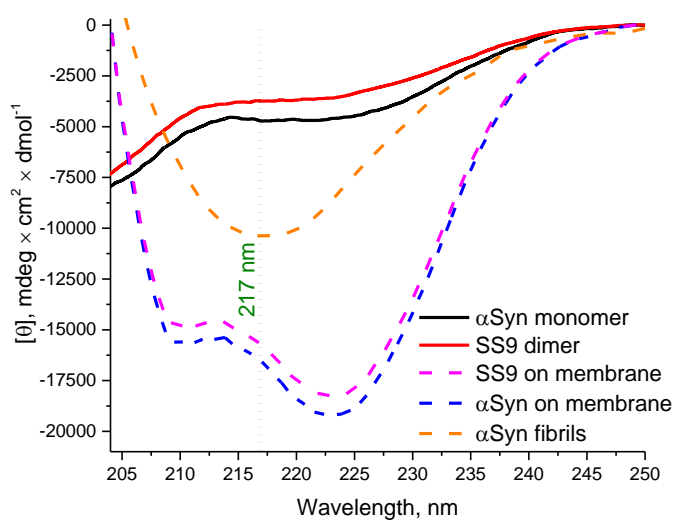

Figure S10. CD spectra of monomeric $\alpha$ Syn (black) and SS9 $\alpha$ Syn dimer (red) in buffer. Dashed blue and orange lines are spectra of membrane-bound $\alpha$ Syn monomer and of $\alpha$ Syn fibrils, respectively. Dashed magenta line is spectra of membranebound SS $9 \alpha$ Syn dimer. Concentration of $\alpha$ Syn in monomeric, fibrillized, and membrane-bound form was $3 \mu \mathrm{M}$. Concentration of SS9 was $1.5 \mu \mathrm{M}$ (the same concentration of amino acids as for monomer). For measurements in membranes the concentration of lipids was $1.5 \mathrm{mM}$ (1000 lipids/ $\alpha$ Syn) that provided complete binding according to the literature data.

\section{SI-8. Test of aggregation propensity of $\alpha$ Syn dimer}

Structure of $\alpha$ Syn disulfide dimers allows them to adopt almost the same conformation as monomeric $\alpha$ Syn in amyloid fibril. Therefore, there is a chance that they would be able to fibrillize by themselves. To test the propensity of $\alpha$ Syn dimers to fibrillize, we incubated $50 \mu \mathrm{M}$ SS18 dimer for 9 days in the absence and in the presence of seeds (WT $\alpha$ Syn fibrils). We observed no indication of fibrillization of dimers. Meanwhile, monomeric $\alpha$ Syn under such conditions readily formed fibrils within few hours in the presence of seeds or within several days in the absence of seeds (Fig S11).

A

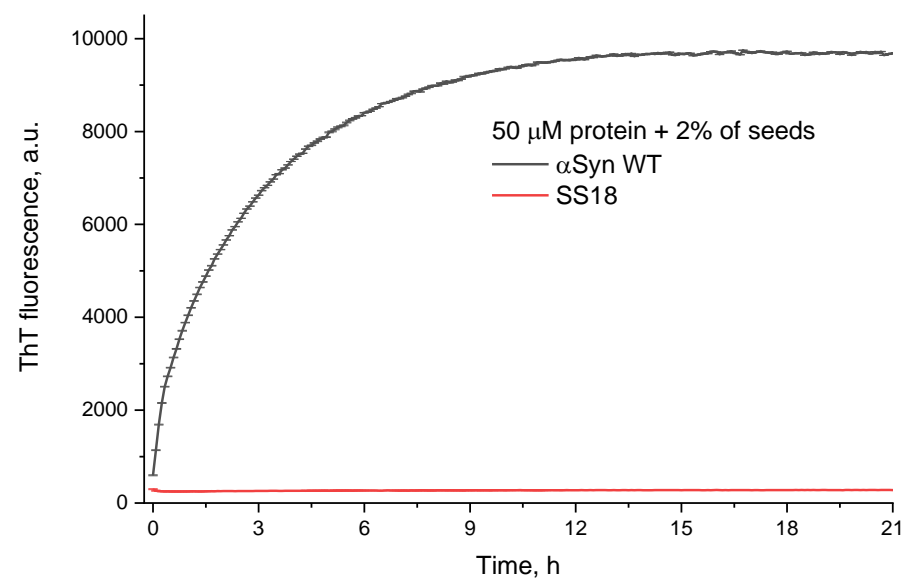

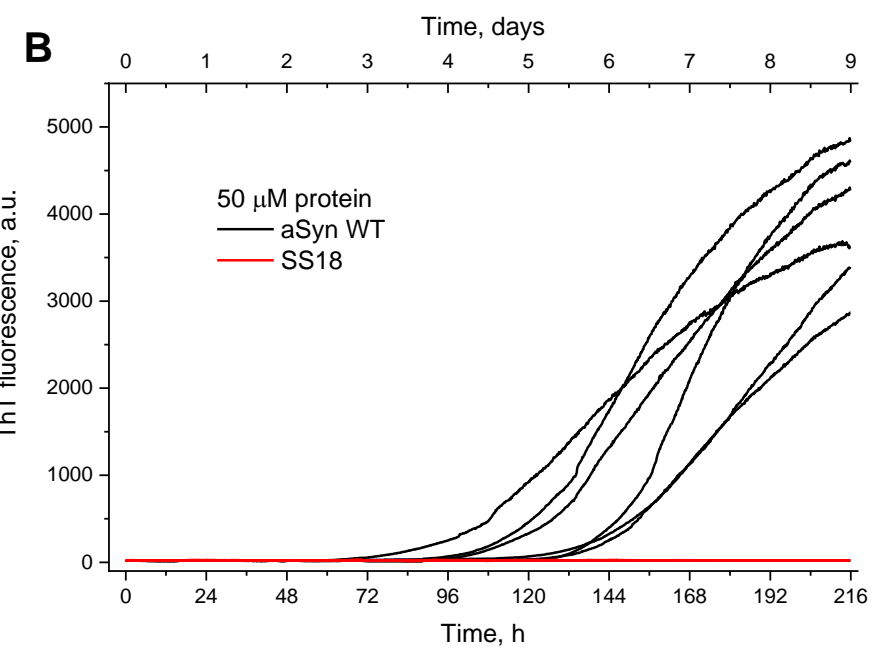

Figure S11. Comparison of fibrillization propensity of $\alpha$ Syn monomer (black) and $\alpha$ Syn dimer SS18 (red) in the presence (A) and in the absence (B) of seeds (WT $\alpha$ Syn fibrils). Concentrations of monomer and dimer were $50 \mu \mathrm{M}$. 
1. Aujard, I.; Benbrahim, C.; Gouget, M.; Ruel, O.; Baudin, J.-B.; Neveu, P.; Jullien, L., o-Nitrobenzyl Photolabile Protecting Groups with Red-Shifted Absorption: Syntheses and Uncaging Cross-Sections for Oneand Two-Photon Excitation. Chemistry - A European Journal 2006, 12 (26), 6865-6879.

2. Shvadchak, V. V.; Afitska, K.; Yushchenko, D. A., Inhibition of alpha-Synuclein Amyloid Fibril Elongation by Blocking Fibril Ends. Angew Chem Int Ed Engl 2018, 57 (20), 5690-5694.

3. Afitska, K.; Fucikova, A.; Shvadchak, V. V.; Yushchenko, D. A., alpha-Synuclein aggregation at low concentrations. Biochim Biophys Acta Proteins Proteom 2019, 1867 (7-8), 701-709. 